\title{
A PROPÓSITO DE IMPRENTA Y LECTURAS EN LA BAEZA DEL SIGLO XVI (SALAMANCA, SEMYR, 2001)*
}

\author{
Juan Miguel Valero MoReno \\ Universidad de Salamanca \& Semyr
}

\begin{abstract}
«... ipse quidem voluendis transeundisque multis admodum voluminibus per omnia semper negotiorum intervalla, in quibus furari otium potui, exercitus defessusque sum, sed modica ex his eaque sola accepi, quae aut ingenia prompta expeditaque ad honestae eruditionis cupidinem utilimque artium contemplationem celeri facilique compendio ducerent...» (Aulus Gellius, Noctes Atticae, pr. 12).
\end{abstract}

Decía Aulo Gelio - y hemos de creerlo- que hurtaba a sus negocios todo el tiempo que podía, para dedicar esos deliciosos intervalos a revolver numerosos volúmenes que transitó siempre en la medida de sus fuerzas. En este ejercicio no dejó, sin embargo, de encontrar fatigas, abrumado por la ingencia de las letras. Así que resolvió tomar del conocimiento módicas cantidades, pequeños montículos o acerbos, a modo de silvas, con los que entendía conducir, a través de la celeridad y facilidad de su compendio, a los ingenios prontos y expeditos de su tiempo, al honesto deseo de erudición y al conocimiento o contemplación de las artes útiles.

Felices ocios, a la lucerna de aquellas noches áticas, tan bien aprovechadas. Aulo Gelio ofrecía a sus contemporáneos de la primera mitad del siglo segundo, a los que desde ahora envidiamos el gusto, una miscelánea de lecturas, selecciones y comentarios, ordo rerum fortuitus. A través de la fragmentación de los discursos que interesan a una determinada comunidad textual e interpretativa somos capaces, gracias a Gelio y a alguno de sus maestros - Frontón o Apolinar-, de reconstruir las lecturas y necesidades culturales de un grupo. Con una lectura cuidadosa, enfrentarlo a un sistema de lectura crítica, a un fértil debate literario-filológico.

Gracias a los ocios bibliográficos de Pedro M. Cátedra, a los desvelos

* A propósito de Pedro M. Cátedra, Imprenta y lecturas en la Baeza del siglo XVI (Salamanca, Semyr [Inventario,2], 2001.

Rlit, LXVI, 132 (2004), 555-576 
de 19 años y unas 6.935 noches —noches biacenses, granadinas, helmánticas, condales, parisinas, colonesas...-, conocemos hoy con precisión todo sobre la imprenta biacense del siglo XVI. En efecto, la totalidad es una ambición colmada de este trabajo de Pedro Cátedra. En esto ha operado al contrario que Gelio. Ha recogido uno a uno los fragmentos, los ha ordenado en un discurso comprensivo. Concha Lois ha elogiado muy justamente el esfuerzo ${ }^{1}$. La $I y L$ no es un mero catálogo. Lo es, y muy riguroso, llevado a los límites de la precisión con que hoy cuenta la tipobibliografía, de la que esta obra va a convertirse en pieza de referencia si una experta de la talla de Mercedes Fernández Valladares no me deja mentir. Como catálogo es de un positivismo estricto. Cada uno de los impresos recogidos es descrito en el pormenor de sus detalles, cubriendo todos los campos actuales de la descripción tipo-bibliográfica, cada uno de los impresos existentes ha sido manipulado directamente, cotejado con otros impresos similares, acompañado de toda la bibliografía pertinente y de sus listas de localización. Podemos observar las variaciones tipográficas, portadas, orlas y demás detalles en las numerosas planchas que acompañan al libro. En definitiva, somos capaces de visualizar y reconstruir críticamente la argumentación. Como catálogo y como libro nos hace trabajar, nos indica filiaciones, rutas, desplazamientos. $I y L$ es un catálogo y una reflexión sobre el catalogar, una lista acompañada de sus herramientas metodológicas, una historia de la imprenta, del libro y de la lectura: la historia de una cultura comprendida en su diversidad.

El catálogo de libros - y otras menudencias- impresos en Baeza constituye la segunda parte del estudio. Son en total 114 páginas que recogen setenta y seis piezas que van fechadas desde el 8 de diciembre de 1550 - un octavo que aúna una traducción anónima, revisada y con prólogo del Contemptus mundi o Imitatio Christi de Kempis y los Cien problemas de la oración de Serafino Aceti da Fermo-, a la última estampa efectivamente conocida de 1599, el Sermón que predicó [...] en la Iglesia Cathedral de la Ciudad de Baeça en las honras por el Rey Don Phelipe segundo de Bernardo de Rojas y Sandoval. El catálogo incluye también tres breves secciones: la primera de ediciones posibles, donde se acogen dos obras de

\footnotetext{
${ }^{1}$ Que sepa, la más madrugadora reseña. Concha Lois Cabello, «Libros y lectores en la Baeza del siglo XVI», Patrimonio Nacional: http://www.patrimonionacional.es/ realbiblioteca/avisos2804.htm : «Si cortos en número son los libros descritos, larga es la ciencia desplegada para arroparlos en un libro nuevo, el que conforma la parte primera de esta Imprenta, un largo centenar de páginas que son un ejercicio infrecuente de verdaderas letras humanas, una armonía de descripción bibliográfica, de estudios literarios y de consideraciones históricas y de pensamiento».
} 
Juan de Ávila, principal impulsor del estudio biacense y de varias de las impresiones para él destinadas; la segunda de ediciones no biacenses, donde se rechaza por motivos tipográficos la pertenencia de otra impresión del Sermón de Rojas y Sandoval a la imprenta de Baeza; la tercera de ediciones inexistentes, la de dos libros muy tempranos - 1554 y $1556-$, ladeados también por motivos tipográficos y ornamentales.

La minuciosidad técnica desplegada en la práctica totalidad de las entradas del catálogo permite reconstruir la materialidad original de la mayoría de ellas a través del aparato tipográfico e iconográfico, donde se estudian las letrerías gótica y romana de la imprenta biacense y algunos de sus elementos de mayor relevancia, como las capitales metálicas y xilográficas. Algunas de sus variantes más importantes han sido recogidas en las ilustraciones del aparato tipográfico e iconográfico. La comparación de los tipos biacenses con los de otras imprentas colindantes, como las de Granada o Sevilla, permite una gran precisión en la atribución de las impresiones y la procedencia de materiales, y explica determinadas condiciones de la industria editorial bética y penibética del siglo XVI. Aparte de las letrerías se estudian también otros elementos menores de la composición, como cruces o éderas, marcas de imprenta, grabados xilográficos y metálicos y complementos ornamentales como orlas, bandas y remates, casi todos ellos reproducidos en lujosas ilustraciones.

Siguen al catálogo nuevos documentos para el trabajo. En la sección «Complemento documental y textual» se incluye la edición del único ejemplar conocido de un pliego suelto titulado Qüistión espiritual (11-VIII-1558) de Juan Carrillo de Guzmán, muestra preciosa de la diversificación que alcanzaron los productos de la literatura espiritual castellana del XVI, y un documento de carácter notarial, una donación de libros a la Universidad de Baeza por el Obispo Francisco Sarmiento de Mendoza (1586) ${ }^{2}$. Es un listado de 112 volúmenes que dan buena idea de los intereses bibliográficos de un alto cargo eclesiástico y de aquellos textos que se consideran fundamentales para el estudio de Baeza. Hay que destacar que esta donación, aunque tardía, constituye la primera auténtica biblioteca de la Universidad de Baeza.

El libro lo cierran una bibliografía completa y puesta al día que conjuga estudios locales con la bibliografía material y teórica más sólida de la crítica internacional. Por fin, se añade un útil índice de nombres y lugares y un índice de láminas.

\footnotetext{
${ }^{2}$ Como ha señalado Concha Lois, figura por errata Diego Sarmiento de Acuña.
} 
Lo cierto es que nos podíamos haber contentado con lo hasta aquí descrito. No lo hace Pedro Cátedra, que dedica casi un par de centenas de páginas, la primera parte del libro, a leer este catálogo.

La sección delantera de esta primera parte, que completa la caracterización técnica con la histórica de la imprenta biacense, está dedicada a la imprenta y los libros de Baeza. La segunda a los libros y autores de Baeza y la tercera a los autores y libros en Baeza.

A partir de aquí persigo hacer una lectura de la realidad y el deseo, teniendo en cuenta las líneas de investigación abiertas por Pedro Cátedra pero sumando a ellas un ángulo de lectura que espero que pueda ser complementario y alimentar el debate. Mi punto de partida es el siguiente; es muy simple: las lecturas ideales recomendadas por Juan de Ávila en su Epistolario y en algunos otros lugares no coinciden con el programa de lecturas que se desprende de los títulos incluidos en el catálogo de $I y L^{3}$.

Reproduzco, a continuación, los fragmentos de los que me sirvo para mi argumentación:

\footnotetext{
${ }^{3}$ Utilizo la edición del Epistolario de Luis Sala Balust, revisada por Francisco Martín Hernández, en Obras completas, V, Madrid: BAC, 1970. El total de esta edición, la más completa a día de hoy, alcanza 252 cartas. La primera edición del Epistolario se imprimió en Madrid: Pierres Cosin, 1578, con el título Pimera y Segunda parte del Epistolario espiritual para todos estados. Contenía 148 cartas. En el muestrario no incluyo avisos para la lectura que no contengan menciones concretas, como en (LXXI, 343): A un estudiante que le escribió la sequedad que hallaba en sus ejercicios: «y si no halláis en la oración aprovechamiento, leed un rato; et inter legendum, meditad alguna cosa conforme a lo que leéis, mezclando la lección con la meditación...». Habrá que tener en cuenta, también, que la mayor parte de las cartas remitidas por Juan de Ávila no están fechadas, así como su difusión manuscrita con anterioridad a la edición biacence perdida y a la madrileña de 1578 . No se tienen en cuenta las referencias a textos bíblicos. Lo cierto es que las entradas que analizo no son demasiado abundantes en comparación con el cómputo total de cartas, y sería más breve sin cartas de carácter instrumental o de funcionamiento interno como [10]. Como es fácil de apreciar no hay recomendaciones de lecturas dedicadas a mujeres, ni siquiera cuando éstas cuentan entre los miembros de la nobleza o abadesas. Hay que considerar, sin embargo, que cada una de las cartas de Juan de Ávila es una lectura intensiva de textos bíblicos, muy en particular los de Pablo, y citas de autores seleccionados casi siempre entre los clásicos cristianos, como Jerónimo, Agustín, Bernardo, Gregorio o Buenaventura - entre los más citados- y, muy parcamente, además de Gerson o el Cartujano, Luis de Granada u Osuna. Juan de Ávila ofrece pues, en general, lecturas digeridas de algunos de los autores de más peso de la tradición cristiana, leyéndolos, parefraseándolos e interpretándolos para sus destinatarios y para aquellos otros destinatarios no implícitos que se encuentran en el horizonte de recepción de lugares como los conventos. Sobre el control de la lectoescritura y las precauciones avilinas puede verse una carta famosa, la que firma en Montilla el 12 de septiembre de 1568 dirigida a Teresa de Ávila sobre el manuscrito de su Vida.
} 


\section{Epistolario espiritual}

[1] [A un predicador, de la importancia de su labor y de la perseverancia] [A fray Luis de Granada, O.P.] [h. 1544] (I, 25-26):

«La segunda que sean muy amigos de la lección, porque seún la gente está durísima esle muy provechoso leer libros de romance. Libros que son más acomodados para esto: Passio duorum, Contemptus mundi, los abecedarios espirituales (la segunda parte y la quinta que es de la oración; la tercera parte no la dexen leer comúnmente, que les hará mal, en que va por vía de quitar todo pensamiento, y esto no conviene a todos); Los Cartujanos son muy buenos. Opera Bernardi, Confessiones de S. Agustín».

(I, 27):

«De lo que yo me he aprovechado en essa parte es la Summa de vitiis et virtutibus de Guillermo Parisién».

[2] [A un religioso predicador que había sido perseguido, confianza en Dios y medios para entender la Escritura] [A fray Alonso de Vergara, O.P.] [¿1535-1547?] (II, 37):

«Parecíame a mí que en leyendo a Sant Juan y a Sant Pablo, y a Isaías, que luego avían de saber la Escriptura, y veo a muchos leerlos, y no saben nada de ella. Y assí veo que si 'aperit' ille 'qui habet clavem' doctorum, nullo alio reserante, scripturae pandentur, ut Hieronymus ait. Yo no sé más que dezille, sino que lea a éstos, y quando no los entendiere, vea algún intérprete sancto sobre ellos, y especialmente lea a Sant Augustín Contra Pellagianos y contra otros de aquella secta...»

[3] [A un predicador; fortaleza; frecuencia de la comunión] [ijesuita?] (IV, 47):

«Destas y otras cosas es menester avisar a los que comiençan a servir al Señor, porque no pierdan por imprudencia la merced que el Señor les ha hecho, y lloren después quando se les aya ido la graçia, la qual no tornará tan presto como se va. Encamíneles en leer vuenos libros, y Vuestra Merced también lea, y ore, y ruegue al Señor por mí».

[4] [A un predicador sobre sus ejercicio por el día y la noche; cómo conducirse consigo mismo y con el prójimo] [Al maestro García Arias, sacerdote teólogo] [2 ¿de enero? de 1538] (V, 52):

«El estudiar será alçando el coraçón al Señor, leer el texto sin otra glossa, si no fuera quando algo dudare, que entonces puede mirar a Crisóstomo o a Nicolao o a otro que le parezca que declara la letra no más: y no se meta sino en saber el sentido proprio que el Señor quiso allí entender, que por agora no es menester leer más».

$(\mathrm{V}, 52-53)$ :

«y querría que ordinariamente leyesse, aviendo algunos mancebos bien inclinados, cada tarde alguna cosa de buenas costumbres, assí como Tulio, o [É]ticas de Aristóteles, o algo de Platón, o cosas semejantes, sin meterse en misterio de cosa de cristiandad, porque de aquellos ha de tenerse aún por insuficiente aun para ser discípulo, y en esto se passará la tarde, y sucederá la orden ya dicha». 
$(\mathrm{V}, 54)$ :

«Item, porque ay algunos que no pueden entrar en el pensamiento de la Passión sino tarde y con mucha pena, es bien que sepa, si fuere uno destos, que es muy buen remedio començar primero a leer algún buen libro devoto de la Passión, y leer aquel passo que entonces quiere pensar, y quédanse en la memoria las circunstancias de aquel passo, y queda la voluntad algo movida. Querría que Vuestra Merced lo hiziesse, y de los libros que para esto me parecen mejor es Passio duorum, o la primera parte del Abecedario Espiritual: provándolos verá qual es mejor. Item se deve exercitar en libros simples, que sean devotos y espirituales, assí como Vitas Patrum, y Casianus, De Collationibus Patrum y De octo vitiis, Summa de Virtutibus et Vitiis, sin el qual no esté. Otro es en gran manera bueno de Henrico Herpio, De duodecim mortificationibus; y éstos bastan por agora» ${ }^{4}$.

[5] [A un sacerdote sobre el agradecimiento a Dios por su condición y la conducta que ha de observar] (VIII, 67):

«... y lea algo que hable de este Sanctíssimo Sacramento, assí como Contemptus Mundi, en el quarto libro, o otros si hallare; mas si con la oración estuviere muy recogido y devoto no cure de leer».

(VIII, 71):

«Los libros en que ha de leer por agora son estos: la Glossa ordinaria, el Nuevo Testamento, y esto después de Vísperas; y en los otros ratos que he dicho de leer han de ser: Contemptus Mundi, Casiano, y a Sant Juan Clímaco, Morales de Sant Gregorio (y este leer no hasta cansar, sino para levantar el coraçón), Meditationes Augustini et Bernardi» ${ }^{5}$.

[6] [A un señor del reino Asistente en Sevilla sobre el ejercicio de gobernar] [¿don Francisco Chacón?] [¿1564?] (XI, 94):

«Ay exemplos de buenos reyes a quien seguir, y castigos de malos que pongan temor: y no sin causa mandava Dios que el libro de su ley fuesse dado a los reyes por mano de los sacerdotes, sino para que, leyendo en él conociessen de cúya mano tenían el reino, y cómo lo avían de governar según las leyes que en la Escriptura divina están. Especialmente servirá para esto la lección de Proverbios, Ecclesiástico y Sabiduría y libro de Reyes, y algunos lugares de los Profetas que tienen particular cuenta con los que rigen a otro; y el Testamento Nuevo, cuya doctrina es más excellente que otra ninguna. Y converná tener una Glossa ordinaria para declaración

\footnotetext{
${ }^{4}$ Citado por Cátedra, p. 89.

${ }^{5}$ Citado por Cátedra, p. 89. Habría que quitar la sordina de los paréntesis a la observación de Juan de Ávila. Coincide con la huella de Savonarola destacada por Eugenio Asensio en el Itinerario de la oración de Francisco de Evia (Medina del Campo: Guillermo de Millis, 1553), texto prohibido en el Índice de 1559: «Como la oración sea para levantar el espíritu a devoción y hervor y deseo, tanto puede durar y alargarse quanto se despertare el tal hervor. Pero quando no se despierta, ni acrescienta el hervor, sino que antes causa hastío y tibieza o pesadumbre, no se deve entonces alargar [fol. 10v]». Vid. Eugenio Asensio, El erasmismo y las corrientes espirituales afines, Salamanca: Semyr [Serie chica, 1], 2000, p. 112. Se trata de una edición revisada y adicionada de la publicación original: Revista de Filología Española, 36 (1952).
} 
de algunos lugares que tengan alguna difficultad. También les aprovechará leer algunos lugares de los Sanctos Concilios de la Iglesia y el Pastoral de S. Gregorio; porque como se tratan en estos libros cosas de govierno ecclesiástico, puédese de allí tomar aviso para el temporal, y también de lo que a los obispos se manda; pues, sacada la administración de los sacramentos y cosas espirituales y de la palabra de Dios, en muy muchas cosas conviene el officio del obispo con el del señor o governador temporal» ${ }^{6}$.

[7] [A un caballero amigo suyo relajado en la virtud sobre el ponerle remedio y esforzarse en ello] (CXLVI, 533-534):

«Los libros que vuestra merced pregunta me parece que le convienen: Confesiones de santo Augustín y Meditaciones; Morales de San Gregorio, Summa mysteriorum fidei, de Titelman, y el Cartujano».

[8] [A un prelado de Granada sobre la importancia de la educación infantil y la enseñanza de predicadores y confesores en los pueblos] [Al Arzobispo Pedro Guerrero] [Montilla, 10 de marzo de 1656] (CLXXIX, 623-624):

«Bien sería que llevasen a los pueblos algunos rosarios de cuentas, y si fuesen cuentas benditas, sería mejor. Item, algunos libros devotos, como los de Fr. Luis, y algunas cartillas».

(CLXXIX, 625):

«Y aprovécheles leer los tratados de Gerson que hablan de esto [la confesión], y mucho más si saben orar y llorar por las ánimas que por tan poco precio se venden al demonio...»

[9] [A un discípulo: modo de vivir y estudiar] [Granada, 1538] (CCXXV, 749-750):

«Interim me parece que entienda en estudiar el Nuevo Testamento, y sería bien sabello de coro. Y llamo estudiarlo el mirar el sentido proprio de él, el cual algunas veces está claro, y otras es menester mirar algún doctor. Y de éstos sean los principales Jerónimo y Crisóstomo; y también puede mirar las Paraphrasis de Erasmo, con condición que se lean en algunas partes con cautela; en las cuales será, luego, cuando discrepa del sentido común de los otros doctores o del uso de la Iglesia. Y estos pasos se deben señalar para los preguntar, o de palabra o de escripto, a quien le informe. Si Crisóstomo alcanzare sobre San Pablo, gran joya es; y para el Nuevo Estamento aprovecha mucho un poco de griego, por poco que fuese, y haya las Annotationes de Erasmo, que en gran manera le aproecharán para esto. Los Proverbios y Eclesiástico son muy buenos; débelos estudiar después del Nuevo Testamento; y después los profetas y demás. Esto cuanto toca a escritura sagrada.

En lo de los libros devotos, tenga por principal a San Bernardo, especialmente In Canticis, y también al Casiano, De Collationibus patrum y De octo vitiis, sin los cuales no esté. Y otros libros devotos que andan en romance, también los haya, que provechosos son.

Resta en lo que toca a los escolásticos, los cuales no podría ansí desenvolver sin maestro; mas no querría que dejase de pasar a Gabriel, que es fácil, aunque del

${ }^{6}$ Es seguramente, de entre todas éstas, la carta más extensa y erudita. En ella cita Juan de Ávila a Platón, Aristóteles, Justiniano y otras autoridades seglares. 
todo no le entendiese, lo cual se podría remediar mucho con señalar lo que no entiende para lo preguntar. La Suma Gayetana ténga algunos casos que se ofrecieren...»

[10] [Nota para hallar lugares comunes para eclesiásticos] [¿Al padre Francisco Gómez?] (CCXXXIII, 771-773) ${ }^{7}$ :

San Juan Crisóstomo, De dignitate sacerdotali, V; San Gregorio, In II tomo suorum operum, prima parte, Pastorali, capitibus 10 et 11; San Gregorio Nacianceno, In Apologetico; San Gregorio, In Vita Moises collationes; San Cipriano, De singularitate clericorum; Gerson, In II tomo suorum operum, Sermone 41; San Gregorio, In secunda parte, Pastoralis, per tota capita; Laurencio Justiniano, In tractatu de regimine praelatorum, capítulos primero y cuarto; San Clemente, In epistola prima ad Iacobum fratrem Domini ibi exibite vos orphanis parentis; Pedro de Blois, Sermones ad sacerdotes; Tritemio, Ad monachos, en Opera temporis; San Buenaventura, In primo tomo Opusculorum, opusculo 16, de praeparatione ad Missam; Gerson, In II tomo Opusculorum suorum Operum; Dionisio Cartujano, In II tomo Opusculoru, opusculo de regimine et vita curam animarum habentium, articulis 13 et 14; Ubertino de Casale, In suo libro sive Arbor vitae crucifixae, in mysterio de Caena Domini; Frías, De arte et modo audiendi confessiones; San Gregorio, In tertia parte, Pastorali, et quarta; Laurencio Justiniano, ubi suora capítulos 78 y 79; Dionisio Cartusano, In II tomo Opusculorum, opusculo de regimine et vita curam animarum habentium, latissime quoad omnia, et qualis se debeat habere in his; San Bernardo, In sermone 44 super Cantica; San Bernardo, in tractatu de conversione, ad clericos; Santo Tomás, Opusculo 65, de officio sacerdotis; San Buenaventura, In primo tomo Opusculorum, opusculo 12 et opusculo 10. Sic de administrando sacramento Paenitentiae; San Agustín [Guillermo de Saint-Thierry, en realidad], X, sermones Ad fratres de monte Dei; Clitobeo, De vita et moribus sacerdotum; [Bernal Díaz de Luco, Obispo de Calahorra], Sobre el aviso de curas ${ }^{8}$.

[11] [A un discípulo sobre alcanzar el reino de los cielos] (CCXXXVI, 780):

«Sería bueno, para pensar los pasos dichos bien pensados, saber la historia cómo pasó, y para esto aprovechará leer a fray Luis de Granada, donde trata de la pasión, o el libro que llaman Passio duorum, u otro que le parezca lo trata bien».

(CCXXXVI, 783):

«Y si quiere tener alguna anchura en saber cómo se ha de hacer esto, lea en la Tercera parte del Abecedario de fray Francisco de Osuna dos letras que allí pone que tratan de esto [traer a Dios a la memoria]».

Audi, filia

[1] [Provecho de pensar en la vida de Cristo] (LXXIV, 228):

«Y los libros que para pensar en la pasión pueden aprovechar, entre otros, son las Meditaciones de san Agustín, en latín, y las del padre fray Luis de Granada, en romance, y el Cartujano, que escribe sobre todos los Evangelios».

\footnotetext{
${ }^{7}$ Para no extender la cita reuniré separados por ';' los títulos que aquí se refieren.

${ }^{8}$ Se trata, como se ve, de una bibliografía sobre el oficio del sacerdocio.
} 
En resumen ${ }^{9}$ :

[1] Abecedarios espirituales: Francisco de Osuna

[2] Annotationes: Erasmo

[3] Arbor vitae: Ubertino de Casale

[4] Cartillas

[5] Cartujanos

[6] Casianus

[7] Confesiones: S. Agustín

[8] Contemptus mundi

[9] Contra Pellagianos: S. Agustín

[10] De arte et modo audiendi confessiones: Frías

[11] De collationibus Patrum

[12] De octo vitiis

[13] De singularitate clericorum: San Cipriano

[14] De vita et moribus sacerdotum: Clitobeo

[15] Ephitoma, Gabriel Biel

[16] Glossa ordinaria

[17] In Apologetico: S. Gregorio Nacianceno

[18] In epistola prima ad Iacobum: S. Clemente

[19] In tractatu de reg. paelaturum: Laur. Justiniano
(3) $(\mathrm{T})$

$(5, E \& A F)(\mathrm{T})$

(3)

(2) $(\mathrm{T})$

(3) (C)

(1)

(1) $(\mathrm{T})$

(2) $(\mathrm{T})$

(2) $(\mathrm{T})$

${ }^{9}$ (1) significa el número de veces que aparece la entrada en cuestión. (T) indica que coincide con un título de la donación testamentaria de Francisco Sarmiento de Mendoza. (C) indica que el título aparece también entre las impresiones que figuran en el Catálogo de $I y L$. $A F=$ Audi, filia.

Cabría desglosar por extenso el repertorio de lecturas recomendadas por Juan de Ávila, al hilo de la ambigüedad que, con respecto a las tendencias oficiales, se manifiesta en este listado. Me limitaré a señalar algunos elementos llamativos. En [11], por ejemplo, las lecturas meditativas que aparecen citadas se encuentran, en ese momento, en la frontera misma de la ortodoxia. No me referiré al complejo problema de los Abecedarios de Osuna, pero cumple recordar la prohibición de algunas de las composiciones de Luis de Granada en el Índice de 1559 (V, 485-486), o la más tardía expurgación (en 1612) de la Passio duorum, un texto castellano que llegó a compartir encuadernación con una obra tan abundantemente prohibida como el Fasciculus myrrhe. Algunos de los títulos seleccionados por Juan de Ávila podía encubrir, de tapadillo, sus versiones romances correspondientes, como la de la Summa Gayetana, prohibida en 1559 (V, 587) o las Vitae Patrum en castellano, prohibidas el mismo año y cuya primera traducción impresa (Zaragoza: 1491) se debió a Gonzalo García de Santa María, el trujamán censurado por fray Ambrosio Montesino en su revisión de las Epistolas y Evangelios. También las Meditationes Augustini tuvieron su correlato romance en las Meditaciones, soliloquio y manual, una compilación apócrifa varias veces editada en Castilla desde 1509 (Valladolid: Diego de Gumiel). Desde luego el nombre más llamativo es el de Erasmo, cuyas Annotationes in Novum Testamentum y sus Paraphrasis in Novum Testamentum había sido prohibidas fuera de la Península Ibérica. Las reticencias de Juan de Ávila (que también incluye en nómina a un enemigo declarado del humanista holandés, el franciscano Titelman) muestran tanto tiento y precaución como atrevimiento. ¿Y Frías? ¿No será, acaso, el franciscano que aparece en un Memorial de herejes huidos de Sevilla (A.G.S., Estados 210)? 
[20] In vita Moises Collationes: S. Gregorio

(1)

[21] Luis de Granada

$(3, E \& A F)(C)$

[22] Meditationes Augustini

[23] Meditationes Augustini et Bernardi

(2) (C)

$(1, A F)(\mathrm{T})$

[24] Morales: S. Gregorio

(2) (T)

[25] Opera Bernardi

[26] Opera: Juan Gerson

(4) $(\mathrm{T})$

(3) (T)

[27] Opera temporis: Tritemio

(1)

[28] Opuscula: S. Buenaventura

(2) $(\mathrm{T})$

[29] Opuscula: S. Tomás

(1) $(\mathrm{T})$

[30] Paraphrasis: Erasmo

(1) $(\mathrm{T})$

[31] Passio duorum

[32] Pastoral: S. Gregorio

(4) $(\mathrm{T})$

[33] S. Jerónimo

(1)

[34] S. Juan Clímaco

[35] S. Juan Crisóstomo

[36] Santos Concilios

(1) $(\mathrm{T})$

[37] Sermones: Guillermo de Saint-Thierry (ps.S. Ag.)

[38] Sermones ad sacerdotes: Pedro de Blois

[39] Sobre el aviso de curas: Bernal Díaz de Luco

[40] Summa de vitiis et virtutibus: Guillermo de París

[41] Summa mysteriorum fidei: Francisco Titelman

(1) $(\mathrm{T})$

[42] Summa peccatorum (Summa Gayetana)

[43] Vitas Patrum

(1) (T)

Si se lee críticamente el cuadro anterior no es posible pasar por alto cierta contradicción entre los postulados de exigencia de la imprenta biacense, que alienta una clara diversificación de las obras de devoción con respecto a la literatura profesional de los teólogos, y las manifestaciones concretas del guía espiritual del estudio, Juan de Ávila, y sus discípulos.

$\mathrm{Si}$ cotejamos las recomendaciones de lectura que ofrece el Epistolario avilino con las obras que tienen pie de imprenta de Baeza, las coincidencias que se reflejan son mínimas, sólo el De contemptu mundi (1550 \& 1591) y las dos ediciones de las Meditationes Augustini (1575 \& 1588).

Caso opuesto, sin embargo, resulta de la lectura del codicilo testamentario de 1586. Las coincidencias aquí se elevan a 20, todas ellas referidas a obras de amplio uso y reconocida ortodoxia en un ámbito más estrictamente eclesiástico y profesional. Sólo salen ligeramente del tiesto, por tratarse de obras contemporáneas o castellanas, el Abecedario espiritual de Osuna que, por cierto, Juan de Ávila recomienda utilizar con tino y prudencia, algunas obras de Luis de Granada, Frías o Bernal Díaz de Luco. El resto de los libros, como digo, poco o nada tienen de sospechoso: la Glosa ordinaria o los Santos Concilios son instrumentales para el uso 
combinado de la Escritura y como memoria jurídica para uso de la Diócesis y sus demarcaciones. Caso aparte es el de Erasmo y las recomendaciones avilinas acerca de la lengua griega, pero como vimos en la entrada correspondiente, el maestro Ávila recomienda suma prudencia, incluso la vigilancia estrecha de un teólogo cualificado. Apenas había pasado un lustro de su confinamiento por el Santo Oficio. Las obras de Agustín, Crisóstomo, Jerónimo, Juan Clímaco, Cipriano, Clemente, Bernardo, Gregorio Nacianceno y Gregorio Magno, Buenaventura ${ }^{10}$ o Tomás de Aquino son lecturas clásicas de la Iglesia perfectamente sancionadas por el uso y obligatorias en la formación intelectual del alto y medio clero, así como la Summa de Guillermo de París es una útil herramienta para la composición de epístolas, sermones, homilías y otros textos domésticos de religión. Otras obras que se pueden encuadernar en este conjunto son las de Gabriel Biel, la Suma Gayetana, Titelman, Justiniano, Pedro de Blois, Tritemio, Saint-Thierry o Clitobeo, piezas sueltas destinadas, también, en general, a profesionales. El Cartujano puede ser entendido como una concesión a las formas relativamente arcaicas de la espiritualidad del Norte, así como Gerson, autor de rabioso éxito en la primera imprenta pero no demasiado representado en el contexto de Juan de Ávila. El Kempis, sin embargo, ya no figura entre los libros que lega el obispo de Jaén.

Cátedra expresa sin ambages que, al menos para la primera etapa de la imprenta biacense (1550-1551) pero, en realidad, también para más adelante «[el] inicio de vida universitaria y de imprenta coinciden, cronológicamente» (pág. 16). En la homogeneidad inicial de esta empresa impresora Cátedra destaca la existencia, cuanto menos implícita, de un programa de lecturas espirituales si bien, y ello es importante, no se puede hablar de vinculación institucional ${ }^{11}$. No debe extrañar esta situación, con todo, pues no hace sino reproducir lo que ya sucedía en otros centros intelectuales consolidados como Salamanca, lugar donde inicia el manchego Juan de Ávila sus primeros estudios, jurídicos, antes de trasladarse a la universi-

${ }^{10}$ En el Catálogo figuran dos traducciones del Pseudo-Buenaventura: Estímulo de amor (Jacobo de Milán), 8-5-1551 y Doctrina cordis (Gerardo de Lieja), 14-8-1551.

${ }^{11}$ Este programa incluiría el Kempis y los Cien problemas de Fermo en primer lugar (8-XII-1550); las Obras del cristiano de Francisco de Borja (1550); los Diálogos espirituales de Catalán (2-I-1551); la Breve summa llamada sosiego y descanso del ánima de Fuensalida (8-I-1551); In te, Domine (14-I-1551), Qui regis, Israel (25-I-1551) y Miserere mei (6-II-1551) de Savonarola; la Perla preciosa (14-III-1551); un Traslado (23-III-1551); el Estímulo de amor de Milán (8-V-1551) y la Doctrina cordis de Lieja (14-VIII-1551) (véase la nota anterior respecto al Pseudo-Buenaventura); un Breve tractado de Díaz (1551) y, podría añadirse le Confesionario \& Vita Christi de Baltanás (¿1551-1552?). 
dad alcalaína, donde cursaría artes y teología entre 1520-1526. Señalo estas circunstancias sabidas porque su experiencia en Salamanca y Alcalá serviría a Juan de Ávila en su posterior labor fundadora de estudios pedagógicos. Aquellos establecimientos impresores, pues, situados estratégicamente en los pivotes de los centros culturales hispánicos se encuentran en su perspectiva de mercado - si se me permite la expresión popular-, en el caldo y las tajadas. En efecto, la imprenta, a despecho de sus orígenes más estrictamente ligados a textos religiosos e incluso a enclaves monásticos, diversifica sus opciones de mercado rápidamente, desplazándose con agilidad de las instituciones docentes y religiosas a las civiles, tanto públicas como privadas. La impresión de modelos oficiales de carta y cédulas, así como los patrocinios locales y nobiliarios de varias obras, a veces muy dispares, dan buena cuenta de ello en la extensión del Catálogo. El propio carácter de los acuerdos de.impresión suele ser, a este respecto, más privado que público.

Bien. Tal y como se configura la recepción y el control del libro impreso hasta mediados del XVI Juan de Ávila, algunos de sus discípulos como Gaspar de Loarte - procesado a finales de 1551 por la Inquisición y acogido enseguida por la Compañía al ser liberado sin cargos-, y la primera imprenta biacense, se estaban jugando el todo por el todo en una España cada vez más dirigida por la ortodoxia contrarreformista. No podemos olvidar que el propio Juan de Ávila había sido procesado por el Santo Oficio a cuenta, no de sus escritos, sino de su predicación en la Diócesis sevillana, pasando un par de años encarcelado - hasta su liberación en julio de 1533. Juan de Ávila fue absuelto sin cargos, pero obligado a una retractación encubierta. No podemos olvidar tampoco - Cátedra no lo olvida, desde luego-, que es en 1551 cuando aparece el primer Índice castellano de libros prohibidos. Si bien éste retoma las listas europeas y, de hecho, ninguno de los primeros impresos biacenses aparece en él, el caso es que es «justamente cuando se interrumpe la producción de nuestra imprenta» (p. 29). La aparición de este Índice provocó la primera oleada consciente de paranoia entre impresores, editores, escritores o traductores y público, y extendió la discreción y la cautela en asuntos espirituales y devotos. El Índice valdesiano de 1559 asestaría el mazazo definitivo a las veleidades espirituales contrarias a Trento ${ }^{12}$.

${ }^{12}$ Las disposiciones trentinas no habrían sido, en todo caso, aplicadas con tanta dureza de no haber existido una tendencia y práctica de control fuerte anterior. Desde el IV Concilio de Letrán (1215) la Inquisición, entonces fuerte, había ido languideciendo generalmente en toda Europa. En España las reformas cisnerianas le conferirían una potencia sin antecedentes. Lo cierto es que las disposiciones de Letrán (1545-1563) acerca de la vigilancia de la producción y lectura de libros son más bien tardías y no demasiado concretas. Por ejemplo la Sesión XVIII bajo Pío IV, el 25 de febrero de 1562, donde se trata de la censura de los libros y de su muchedumbre. Los resúmenes de las sesio- 
Juan de Ávila conoció la dirección del viento, las bromas eran las justas en esa España que en 1559 encarcela y destituye nada menos que al Arzobispo de Toledo, Bartolomé Carranza. Por eso Juan se echa las manos a la cabeza cuando aparecen - supuestamente sin tener él noticia-, 'sus' Avisos y reglas christianas en la prensa complutense de Juan de Brocar (1556), al impulso de un librero arrobado por las enseñanzas del maestro, Luis Gutiérrez. Ávila, preveyendo los posibles resultados de esta edición pirata que, por el origen de las prensas, estaba destinada a un conocimiento amplio, entonó la salmodia exculpatoria correspondiente. El Audi, filia, es decir, los Avisos, que era una obra iniciada en años más mozos, enderezada a la tutela espiritual de la asceta montillana doña Sancha de Carrillo, tuvo que cambiar de rumbo. No era una obra destinada inicialmente a la imprenta y tuvo múltiples redacciones. Las modificaciones de la última de ellas, en la que le alcanzó la muerte a Juan de Ávila, no eran tan esenciales como cabía esperar, pero sí muy significativas. Juan de Ávila escribe un aviso excusando la responsabilidad de aquella primera edición que se hizo sin conocimiento suyo, cambia también el destino de la ya cadáver Sancha de Carrillo por un destinatario general y ejerce ciertos cambios que se pueden resumir en una multiplicación de citas bíblicas y de estricta ortodoxia — con especial referencia a los Padres y Doctores de la Iglesia - y a un entibiamiento de su inicial aperturismo - llámese éste erasmismo, alumbradismo e così via - generalizado a toda la obra.

Las precauciones del propio director espiritual y tutor editorial, en parte, de las prensas biacenses, me inclinan a pensar que el carácter ambulatorio e inestable de algunos impresores y libreros de la primera mitad del XVI puede, en efecto, explicar la falta de datos de impresor en la primera docena de entradas del Catálogo de impresiones baezanas pero también que no sólo las difíciles condiciones comerciales - Cátedra hace una excelente reconstrucción de los ritmos de trabajo, poco vivos, de esta primera imprenta- sean las causantes del anonimato; también las difíciles condiciones de libertad intelectual y espiritual.

A pesar de todas las dificultades Juan de Ávila no cejó en su promoción y empuje pastoral. Vuelvo hacia atrás. Poco después de abandonar las cárceles del Santo Oficio inicia su periplo por el Sur peninsular. En Córdoba conoce a Luis de Granada y afinca su influencia en Montilla y localidades aledañas. Funda instituciones de enseñanza como el Colegio de San Pelagio o el Colegio de la Asunción, primeras pruebas para la empresa de más aliento que fue la Universidad de Baeza. Se desplaza también a Gra-

nes marcan las líneas de la gestión del control, pero son comisiones variadas, a veces impulsos personales, los que van conformando las listas nutridísimas de las que habla el Concilio. El Índice de Valdés es una formulación rigorista de una postura en realidad más flexible. 
nada (1536), llamado por su Arzobispo, Gaspar de Ávalos, y allí sucede uno de los múltiples capítulos evangélicos de Juan, cuya máxima expresión sería la conversión del Duque de Gandía, Francisco de Borja, luego religioso celosísimo, principal de la Compañía y uno de los primeros autores impresos en Baeza. Sucede, digo, una conversión que pudo colmar el espíritu de emulación paulina del manchego, la del soldado y luego ¡librero ambulante! Juan de Dios ${ }^{13}$.

La identificación de Juan de Ávila, pues, con las instituciones pedagógicas, el mundo del libro y de la imprenta y los crentros donde se asientan y desde donde se difunde el mensaje de las instituciones y los comercios es muy clara. Esta dimensión amplia de Juan de Ávila hay que tenerla muy en cuenta porque, por muy inestable que sea una imprenta, como la baezana, irregular su producción, pobre en recursos y medios, tanto materiales como estéticos, humilde o simple su tipografía, guadianesca su existencia, en suma, ésta no puede ser considerada como núcleo independiente ${ }^{14}$. La imprenta hispánica del XVI conforma una malla tupida de relaciones comerciales, intelectuales y, al final del camino, muy concretas, personales y clientelares, que exceden siempre los límites de la localidad. El carácter traslaticio o transhumante de muchos impresores y libreros, el trasiego e intercambio de material tipográfico, rutas e ideas, entre los profesionales, la relación estrecha o la desvinculación con el autor, el control estrecho de la autoridad en una banda ancha de protocolos que va de la lectura del párroco local y sus admoniciones a las tasas obligatorias para el libro, dadas a muchas leguas del lugar de producción, el patrocinio, los tanteos del mercado y las contradicciones de la recepción - las lecturas deseadas y las efectivamente impresas, la aparición de intereses literarios antes desconocidos... Hay una suerte de equivalencia entre el continuo transitar andaluz de Juan de Ávila y el mundo giróvago del impresor y el librero. La prueba es que con el establecimiento algo más sólido de la segunda etapa de la imprenta biacense (1553-¿1558?) la relación con Sevilla o Granada, los dos grandes centros impresores del Sur, se fortalece, al menos en un sentido estadístico, que luego se confirmará como progresión conforme avance el siglo y la ascendencia directa de Juan de Ávila y sus discípulos se vaya desvaneciendo progresivamente.

El primer impresor que firma con su nombre en Baeza es Fernando Díaz

${ }^{13}$ Esta Granada, centro impresor del Sureste, es todavía entonces un lugar abierto a las nuevas ideas. En 1534, por ejemplo, se habían impreso unos Libri minores - los textos estrella de los primeros pasos educativos - con algunas diferencias de peso con respecto a las habituales impresiones complutenses de Arnao Guillén de Brocar o Miguel de Eguía. A los Liber Catonis, Contemptu mundi, Fabulae Aesopi, Floretus o Dichos de los sabios, se añade ahora una Institución del Caballero Cristiano.

${ }^{14}$ Aunque más adelante argumentaré, también, la diferencia de la imprenta biacense dentro del contexto general con el que establece relaciones. 
de Montoya. Todos los documentos disponibles y el deslinde de su posible biografía los analiza Cátedra con puntillismo. Ahora nos interesa el carácter provisional, incluso improvisado, de su taller, la escasez de su trabajo como impresor, la gran cantidad de errores textuales con respecto a la etapa anónima anterior o la práctica del alquiler de tipos. Todo ello conduce a pensar en un pluriempleo razonable del impresor. Producción paupérrima, documentos fabricados para su uso en serie - una carta de venta y otra de venta e imposición de censo- y un tríptico espiritual (1553) de Alonso de Orozco dirigido a la abadesa de Santa Clara de Montilla que enlaza con la producción de la etapa anterior. Eso es todo.

De 1556 a 1568 sólo se producen modelos de carta, con la excepción de una traducción de Francisco Barba de la Fundación de la sagrada orden de la santíssima Trinidad de redempción de captivos de Robert Gaguin, texto no extraño en una región próxima a la África de los Baños de Argel, y una interesante Qüistión espiritual de Juan Carrillo de Guzmán (1558 o ¿1563?) que edita Cátedra en su Apéndice (pp. 333-340). Este texto fue examinado por la Inquisición granadina. Todas estas piezas van firmadas o son atribuibles a Fernando Díaz de Montoya. El balance de la literatura espiritual, en comparación con la primera etapa es, como se ve, mucho menos significante. Cátedra ha querido explicarlo, como ya avancé, porque «a partir de mediados de los años cincuenta la Inquisición no dejará de acosar a los maestros de la Universidad de Baeza hasta los años ochenta del siglo XVI» (p. 52).

La tercera etapa (1568) de la imprenta biacense, un sólo libro, un sólo impresor - Juan Bautista de Montoya- se limita a una curiosidad no exenta de valor artístico, por los grabados que la acompañan. Es obra de encargo de un ilustre de la ciudad de Baeza, su regidor, Antonio Flórez de Benavides, dedicada a Juan de Austria, a quien Flórez endereza su propia traducción de la obra del napolitano Federico Grisone, Reglas de la cavallería de la brida.

Las ínfulas letradas del Regidor se manifestarán en la cuarta etapa (1574-1600). Se concentra en ella más de la mitad del Catálogo; entradas 35 a 74. Esta etapa, de relativo asentamiento después de la laguna de media docena de años, la domina por completo el impresor Juan Bautista de Montoya - con las lógicas dudas de menudencias de imprenta que van sin firmar, un total de 15 cartas, por ejemplo, de las 39 entradas. La relación comercial con Granada y con el mercado hispalense se intensifica. La prensa biacense se hace acreedora en esta nueva andadura de un título emblemático de la cultura europea, el Examen de ingenios de Huarte, estampado en 1575 y de nuevo en 1594. Dejaré la literatura religiosa y espiritual para el final y repasaré, al vuelo, el resto de los impresos.

Un rasgo acentuado de esta etapa es el espíritu representativo cívico. La dedicatoria de las Reglas de la cavallería de la brida a Juan de Aus- 
tria va en esa dirección. Puede hablarse, en la medida que lo permiten las estadísticas, de un cuerpo cívico de principales, por lo general, que encuentran en la imprenta un medio efectivo de satisfacer sus necesidades intelectuales, por un lado, y de encontrar voz, representación e imagen allí donde sus fuerzas reales no se extienden. Acunadas por el prestigio del libro - cuyo poder es resaltado por la censura - y este carácter representativo ligado a una mentalidad cortesana (de provincias) aparecen el resto de las traducciones del italiano de Flórez de Benavides, como el Tractado de la tribulación de Bonsignore Cacciaguerra, dirigido al Obispo de Segovia Diego de Covarrubias y Leyva - aprobado por la Compañía en Madrido La historia del señor Francisco Guichardino -encaminada a Antonio de Pazos, Obispo y Presidente del Consejo supremo de España. El Tractado de la tribulación creo que se complementa bien con el éxito editorial biacense - así parecen sugerirlo sus repetidas impresiones- de las dos partes del Honesto y agradable entretenimiento de damas y galanes, otra traducción del italiano en este caso de Francisco Truchado, vecino de Baeza, impreso con seguridad en cuatro ocasiones e hipotéticamente una más. Hay que añadir la traducción de la obra de Monseñor de Sabba Castiglione, el Cavallero Avisado, cuya segunda parte se imprime dos veces. Honestidad, prudencia, caballería cristiana y cierto quietismo civil son componentes de la república cristiana que se pretende proyectar como imagen de la Contrarreforma. Se concibe como ideal el civismo y un moderado espíritu cortés en comunión con una fe sólida y poco dada a especulaciones interiores. Estos libros venidos desde Italia actúan pues, como modelos del urbanismo romano de Trento.

La faceta pedagógica de uno u otro signo es, en realidad, esencial en esta etapa. Las Dos obras muy provechosas (1574) de Antonio de Escalona es un texto de doctrina para la crianza de niños. El Libro llamado el hombre nuevo (1582) de Miguel Sánchez de Ortega es un curioso ejemplar de doctrina evangélica, una cartilla dialogada de la ortodoxia cristiana decantada de forma especial para hombres del campo y captivos, así como todos aquellos que se encuentran en lugar donde no pueden oír de primera mano la doctrina evangélica (una especie de cuaquerismo espiritual, por otro lado) ${ }^{15}$. Sumamos un libro de medicina, el Libro primero de Annathomia (1590) y, por fin, un arte epistolar muy interesante de Gaspar Salcedo de Aguirre, doctor en la Universidad biacense, titulado Pliego de cartas en que ay doze epistolas escritas a personas de diferentes estados y officios (1594; pero fecha en la fe de erratas de 27 de junio de 1595) ${ }^{16}$. Añado las dos impresiones, ya comentadas, del Examen de ingenios.

\footnotetext{
${ }^{15}$ Fue Miguel Sánchez canónigo de la catedral de Baeza y mantuvo relaciones estrechas con la Universidad. Asistió a Trento. Vid. Cátedra, p. 157.

${ }^{16}$ Sobre la difusión de este ingenioso libro puede dar idea la lista de ejemplares conservados que cita Cátedra en la p. 269.
} 
Por otro lado podemos reunir dos piezas curiosas: una de ellas es la Relación muy verdadera (1594) de Alonso Becerro, relación de sucesos cuya existencia se explica por la gran proliferación de este género editorial en todos los centros impresores y por su tema, la tortura y el martirio de unas monjas católicas a manos de los luteranos, texto en prosa que va acompañado de unas poesías religiosas de ciego, al propósito; la otra es una $\mathrm{Me}$ moria de 1595 acerca del descubrimiento, en las inmediaciones de Granada, de documentos y cuerpos de santos y mártires, otro género de suceso religioso.

Me resta hacer un repaso rápido de los libros que pueden caracterizarse genéricamente como de religión y/o espiritualidad. Por supuesto, existen puntos tangentes con algunos de los libros que acabo de mencionar, así el Libro llamado el hombre nuevo o el Cavallero avisado, pero no me parece del todo irrazonable esta separación un poco rígida que aquí hago.

De otro lado, en este apartado quizás hay que conceder mayor importancia a los productos que no figuran en el Catálogo que a los que se imprimen. Pensemos, por ejemplo, que la impresión de bulas no tuvo privilegio en Baeza, o que no se estampó un producto tan popular como el libro de horas, cuyo monopolio, en este cuadrante geográfico, parece pertenecer a Granada. Diría que se pueden establecer dos productos - divisibles luego en función de los intereses de cada investigador. Por un lado, un pequeño cuerpo de doctrina y literatura espiritual; por otro, los impresos de carácter oficial relacionados con las necesidades institucionales de la propia Iglesia baezana o la Diócesis jienense:

[A]

San Agustín, Las meditaciones, y soliloquios (1575 y 1588).

Juan de Ávila (ante 1578: sin ej. conservado).

Kempis, Contemptus mundi y Luis de Granada, Tratado de oraciones y ejercicios de devoción (1591).

Francisco Sarmiento de Mendoza, Diálogo de la doctrina christiana (1591).

Diego Pérez de Valdivia, Aviso de gente recogida, y especialmente dedicada al servicio de Dios (1596)
[B]

Constituciones Synodales, hechas por don Francisco Sarmiento (1587).

Bernardo de Rojas y Sandoval, Sermón que predicó [...] en la Iglesia Cathedral de la Ciudad de Baeça, en las honras por el Rey Don Phelipe segundo (1599).

En comparación con la primera etapa de la imprenta biacense la muestra no cabe considerarla más que pobre, aunque de gran interés. Como ya se apuntó, el encastillamiento religioso frenará en España la producción 
impresa de libros espirituales y devotos que no concuerden de forma oficial con las pautas de la Contrarreforma ${ }^{17}$. Aunque las prácticas espirituales de Juan de Ávila siempre debieron parecer sospechosas, a tenor del cambio de orientación en la selección de títulos de la imprenta baezana, y muchos de sus amigos estuvieron en vigilancia o fueron condenados, la imprenta de Baeza parece servir una especie de homenaje póstumo, o cuanto menos tardío, a sus primeros tutores. El Epistolario de Ávila se publica tras su muerte. Su difusión anterior es manuscrita. El Kempis - cuya traducción se atribuía a Ávila o a Granada - acompaña, no por casualidad, a una recopilación de oraciones y ejercicios devotos a tres años pasados del deceso de Luis de Granada. Diego Pérez de Valdivia, discípulo dilecto de Ávila, alumno de la Universidad de Baeza y profesor de artes en la misma a partir de 1549 era ya mayor cuando aceptó el cargo de catedrático de Teología en la Universidad de Barcelona por indicación de Felipe II y se publica su Aviso. Pérez de Valdivia, como el mismo Ávila y otros compañeros de promoción, Loarte o Carleval, pasó apuros con la Inquisición, vista su condición de descendiente de conversos y su relación con el mundo de las beatas del Sur. Precisamente, en el Aviso, establece una pequeña guía de lecturas, no tanto femeninas, como adecuadas, también, a un destinatario femenino ${ }^{18}$. Las aguas debían seguir estando turbias, de todos modos, cuando Bernardo de Rojas se molesta porque en Baeza se imprima sin aviso un sermón suyo que no tenía nada contra la fe. Sin embargo, las prensas que durante años callan retoman simbólicamente a aquellos que la impulsaron en su primera etapa.

El caso de la imprenta baezana es muy llamativo. Si no exageramos la dependencia con las imprentas granadina, sobre todo, y la sevillana, que es técnica o económica, se observa que ésta funciona con relativa independencia. Si cotejamos las listas de productos impresos en Sevilla o Granada de 1500 a 1600 con la biacense, las coincidencias son mínimas: el Honesto y agradable entretenimiento del baezano Truchado, si acaso, impreso en Granada en casa de Rene Rabut (1582; al fin: 1583). Quizás ambas imprentas habrían sido más paralelas de haber triunfado la orientación pretendida por Hernando de Talavera cuando llega a Granada en 1496, después de haber buscado impresores en Sevilla para establecer prensas donde tanta falta hacían a la defensa de la fe cristiana. Ya se habló, rápidamente, de

${ }_{17}$ Por contraponer un ejemplo de la primera etapa, el Confesionario o la Vita Christi (no conservado; $\mathrm{n}^{\circ} 13$ del Catálogo) de fray Domingo de Baltanás, autor tan a menudo impreso en Sevilla y que, amigo de Ávila, «compartía intereses espirituales y educativos» (p. 72). Pues bien, éste fue procesado y reducido al ostracismo.

${ }^{18}$ Las recuerda Cátedra (p. 92): vidas de santos, en especial la de San Francisco, Luis de Granada, Juan de Ávila, Osuna, Laredo, Ángela de Foligno, Catalina de Siena, Contemptus mundi, Escala de Juan Clímaco, Flos sanctorum. La cuota reservada para los contemporáneos es ya suficientemente significativa. 
los intereses civiles, pero es evidente que fue la Universidad y su corporación de profesores y alumnos la que tuteló, en gran medida, la producción impresa en Baeza. A diferencia de las otras fundaciones del Sur - Granada, al amparo de la Corona (1532); Sevilla, por iniciativa eclesiástica (1505) u Osuna, por voluntad del cuarto conde de Ureña (1494)_, la Universidad de Baeza nace de la voluntad de un clérigo mediano en buenas disposiciones con la curia romana y Paulo III, Papa al que Rodrigo López arranca la bula de fundación como Colegio que luego ampliarán y fundamentarán Juan de Ávila y sus discípulos de forma definitiva desde 1542.

Este libro de Pedro Cátedra, al estudiar con minuciosidad las relaciones internas entre los personajes - Juạn de Ávila y sus discípulos, los impresores, libreros, obispos, regidores... - y su contexto mercantil -la historia de la imprenta y la circulación y difusión del libro- e institucional - la Universidad, la Iglesia, la Inquisición, las corporaciones civiles y religiosas...- consigue desvelar la trama de relaciones entre lo estrictamente local y su trascendencia nacional e, incluso, internacional, desde la familiaridad de Rodrigo López con el Papa, a la red de fundaciones educativas y conventuales, el resto de las universidades españolas, el trato cercano de los responsables del libro en Baeza con las figuras señeras de la espiritualidad del XVI y sus órdenes en tanto que instituciones religiosas y jurídicas.

Este uso combinado de la memoria y el archivo permite ubicar a la imprenta biacense en el púzle de la interpretación cultural. Su lectura admite tanto las semejanzas con el conjunto como comprender la particularidad y la diferencia de esta imprenta y el mundo de discursos que la rodea. La relación de Ávila con la Compañía, incluso la relación directa con Ignacio de Loyola, nos ayuda a comprender, desde esa macroestructura, cuáles eran las solidaridades y competencias en las que se encontraba inserta la pastoral bibliográfica avilina, pero su negación a ingresar en la Compañía también es un índice de independencia que justifica, hasta cierto punto, la alteridad de la producción espiritual biacense y que convierte a Baeza en un «verdadero laboratorio para la espiritualudad del siglo XVI» (p. 146).

En este sentido Cátedra elabora un concepto de poética literaria que, espero, desarrolle en investigaciones ulteriores, pues lo considero central: desviación genérica ${ }^{19}$.

\footnotetext{
${ }^{19}$ Paralelamente, pero coincidiendo en lo esencial, María Sánchez Pérez y yo mismo hemos hablado de apertura genérica para el caso de los pliegos sueltos de relaciones de sucesos en los que se combinan prosa y verso. Quizás desviación tenga una sombra de prejuicio en comparación con apertura, aunque no es lo que se pretende, en verdad.
} 
Para el lector no habituado los libros de espiritualidad pueden dar la impresión de unidad temática y, en efecto, son muchos los bloques móviles que se rellenan con citas al propósito y cuyos dispositivos textuales y formales son muy semejantes, por ejemplo, si nos referimos a los tres pasos de la ascesis tradicional: lección, meditación, oración; o cuando se trata de un tema sacramental. Esta impresión uniforme tendría incluso una dimensión europea si consideramos que «lenguaje simple, tonos afectivos, piedad cristocéntrica, tenían especial relevancia y eran marcas (subrayo yo) de estilo, teniendo en cuenta además que muchos de estos textos tenían un primer destino femenino, como se demuestra en los prólogos de los libros de devoción italianos publicados entre 1475 y 1529» (p. 94).

Tanto autores como impresores tratan de diversificar su producción para adaptarla a nuevos públicos, exigencias lectoras y distintas destrezas, grados de competencia y tecnologías de lectura. De hecho, la homogeneidad aparente que sugiere la cita ánterior se disuelve ante la siguiente formulación a propósito de los Diálogos espirituales de Baltasar Catalán, a los que Cátedra dedica unas páginas imprescindibles:
«el interés de estos Diálogos espirituales no estribará en la renovación formal por medio de una correcta militancia retórica o en la elección de un modo de escritura que, tal como se nos elabora, no deja de ser muy añejo, sino más bien en el proceso de desviación genérica que implica el abandono de un género pastoral con destinatarios colectivos y con los elementos propios de la difu- sión oral, como es el sermón, en beneficio de la catequesis relativamente autosuficiente, que sólo se reconduce por el camino de la lectura privada. Gracias a lo cual la doctrina tradicional puede repercutir con un nuevo senti- do, en sintonía con los tiempos y con determinados ambientes...» (p. 146).

La fluctuación genérica, el préstamo y la reelaboración formal que permiten el paso o la conviencia del sermón y el diálogo — formas ambas que compartían algunos casilleros genéricos- deben conducirnos, entonces, a una reformulación de la poética de la literatura espiritual española del siglo XVI. Es éste comportamiento discursivo y textual, en definitiva, el que favorece la existencia de libritos de mano como la Perla preciosa, cuya formulación sólo se entiende desde la reflexión acerca de los nuevos públicos, sus necesidades y limitaciones. Esta obrita, que según Cátedra ejemplifica «cómo la imprenta de Baeza cubre casi todos los frentes de las prácticas devocionales entre laicos» (p. 154) está pensada desde una dimensión interior en la que confluyen lo efectivamente espiritual y el gusto por los elementos estrictamente literarios o narrativos interesantes para un público seguramente formado por mujeres e incluso niños. Sólo hará falta recordar las fascinaciones literarias de Teresa de Ávila o, desde otra perspectiva, la superabundancia de libros de caballerías en la imprenta sevillana. Este hecho provocó una relajación compositiva que dio cabida a lo apócrifo y a la seducción textual frente a la exposición árida para especia- 
listas en teología e intelectuales de la iglesia. Esta vocación pastoral de apertura genérica, pero también conceptual y espiritual, amenazaba con la desvertebración del código, con lo que la necesidad de dispositivos y estrategias de control se echó de ver enseguida. Juan de Ávila, en efecto, recomienda en su Epistolario los libros anteriores a la desviación. Seguro que no dudaba de la bondad de esta abdicación, quizás algo más de sus efectos entre los nuevos lectores. La donación para que la Universidad de Baeza estrenara biblioteca coincidía en parte con la lista avilina y con las lecturas posibles dentro de lo permitido en los índices. Lo que en un momento dado había sido posible, la identificación de la producción impresa con sus receptores y la formación de bibliotecas ${ }^{20}$, se abre en una $y$ griega, en una renuncia dolorosa.

Creo por eso, ésta es mi lectura propia, que este libro, además de tantas cosas, es una hermosa reflexión sobre las ideas de apertura y cierre, sobre cómo la cultura - en este caso la impresa - se manifiesta en la respuesta a esta tensión.

${ }^{20}$ La reflexión sobre la formación de las bibliotecas es otro alero teórico que aborda Cátedra en un libro reciente que, investigando otros problemas, complementa los estudiados en Imprenta y lecturas en la Baeza del siglo XVI o el también próximo Invención, escritura, edición difusión y recepción de la literatura de cordel (siglo XVI), Mérida: Editora Regional de Extremadura, 2001. Se trata en este caso de la formación, disposición y dispersión de una biblioteca nobiliaria, la de Alonso de Osorio, VII Marqués de Astorga, donde la combinación del estudio de las materias y las formas del libro, un hilemorfismo teórico, da las pautas para la comprensión de lo que reza su título: Nobleza y lectura en tiempos de Felipe II. La biblioteca de don Alonso Osorio Marqués de Astorga, Valladolid: Junta de Castilla y León \& Consejería de Educación y Cultura, 2002. 


\title{
RESUMEN
}

\section{A propósito de Imprenta y Lecturas en la Baeza del siglo XVI (Salamanca, Semyr, 2001), por Juan Miguel Valero Moreno.}

La imprenta en Baeza, como enclave tecnológico, y su producción bibliográfica (15501599), catalogada, descrita e interpretada por Pedro M. Cátedra, constituye un observatorio privilegiado, aunque angular, en el contexto espiritual e intelectual condicionado por la Contrarreforma. En ese especial laboratorio de la espiritualidad del siglo XVI se llega a un análisis complementario de las instituciones pedagógicas (la Universidad biacense, por supuesto), y el mundo del libro y el de la imprenta, en su especificidad local, pero sobre todo en su conexión y posición nacional e internacional, a través de la reflexión sobre el catálogo y los condicionantes materiales de la imprenta biacense. Se subrayan las diferencias y afinidades de los progamas espirituales y de lectura representados por Juan de Ávila y la evolución de la imprenta en Baeza, así como la conformación de una nueva poética del texto espiritual impulsada por la imprenta y representada en el concepto de desviación genérica, esto es, la adaptación del texto a una variedad diversa y cambiante de destinatarios y el pulso que los nuevos textos mantienen entre la demanda y el control espiritual, lo ortodoxo y lo heterodoxo, la apertura y el cierre.

Palabras clave: Imprenta, Historia del Libro, Contrarreforma, Espiritualidad, Baeza, Juan de Ávila, Desviación genérica.

\begin{abstract}
Printing in Baeza, as technological point and its bibliographic production (1550-1599), catalogued, described and interpreted by Pedro M. Cátedra establish an outstanding point of view over the spiritual and intellectual context determined by the Counter-reformation. In this special laboratory of xvith century spiritual life it become to a complementary analysis of pedagogical institutions (the University of Baeza, of course), and the world of printing, in its local specifically, and its national and international connection and position through the reflection about the catalogue and the material circumstances of biacense printing. The differences and affinities of the spiritual programmes and lecture represented by Juan de Ávila are outlined, also the evolution of printing in Baeza, and the conformation of a new poetic of spiritual references to a diverse and changing variety of public and the tension that new texts hold out between demand and spiritual control, orthodoxy and heterodoxy, opening and closure.
\end{abstract}

Keywords: Printing, Book History, Counter-reformation, Spiritual Life, Baeza, Juan de Ávila, Generic deviation. 